\title{
Whither hospital linen? Two centre observational study of alien hospital linen
}

Phillip Moradi, Jed Rowe, Stephen Washington

Selly Oak Hospital, Birmingham B29 6JD

Phillip Moradi house officer Jed Rowe consultant geriatrician Withington Hospital, Manchester M20 8LE

Stephen

Washington senior house officer

Correspondence to: J Rowe

jedrowe@

geriatrickery. freeserve.co.uk

BMJ 1999;319:1614
An efficient linen service is a priority for any institutional healthcare system. ${ }^{1}$ Many sheets and pillowcases disappear, and pilfering has been considered as one explanation. ${ }^{2}$ In an effort to designate ownership and presumably to prevent theft, some units have stamped their laundry with an identifiable trust logo. We noticed that some hospital linen bore logos signifying a distant origin, and we used these marks to explore the movement of such items.

\section{Methods}

The source of alien hospital linen was identified by two junior doctors during the course of routine ward work in hospitals in Birmingham and Manchester. The logos of all observed pillowcases and sheets from outside these two cities were recorded during October 1999. Pyjamas and nightdresses were not included as they were considered more likely to be dispersed by interhospital transfer of patients. Each item's provenance was then used to produce a compass bearing indicating its direction of travel. Vectors produced for each centre suggest the overall direction of travel of the linen. To allow for the discontinuity in compass bearings at true north, a displacement relative to the pole was calculated for each item's direction of travel. The vector, given as a compass bearing, is the mean of the displacements from geographical north.

\section{Results}

A total of 192 sheets and pillowcases were observed from 19 trusts in 14 towns or cities. In each case the origin was south of the centre where the observation was made. In Manchester 65 of the 95 sightings were of linen from north of Birmingham. Linen from London came from six trusts. The origin and direction of travel of individual items are shown in the table. Derived vectors produced a bearing of 348 degrees for linen seen in Birmingham and 344 degrees for the Manchester sample.

\begin{tabular}{|c|c|c|c|}
\hline $\begin{array}{l}\text { Observation } \\
\text { point }\end{array}$ & Origin & $\begin{array}{l}\text { No of } \\
\text { items }\end{array}$ & $\begin{array}{c}\text { Direction of travel as } \\
\text { compass bearing (degrees) }\end{array}$ \\
\hline \multirow[t]{11}{*}{ Birmingham } & London & 43 & 313 \\
\hline & Cheltenham & 15 & 10 \\
\hline & Bristol & 13 & 20 \\
\hline & Bath & 12 & 14 \\
\hline & Gloucester & 5 & 15 \\
\hline & Hereford & 5 & 50 \\
\hline & Swindon & 2 & 350 \\
\hline & Bournemouth & 1 & 356 \\
\hline & Salisbury & 1 & 355 \\
\hline & Stoke on Trent & 40 & 355 \\
\hline & Warwick & 20 & 343 \\
\hline \multirow[t]{4}{*}{ Manchester } & Derby & 16 & 320 \\
\hline & Leicester & 9 & 320 \\
\hline & Coventry & 6 & 338 \\
\hline & London & 4 & 326 \\
\hline
\end{tabular}

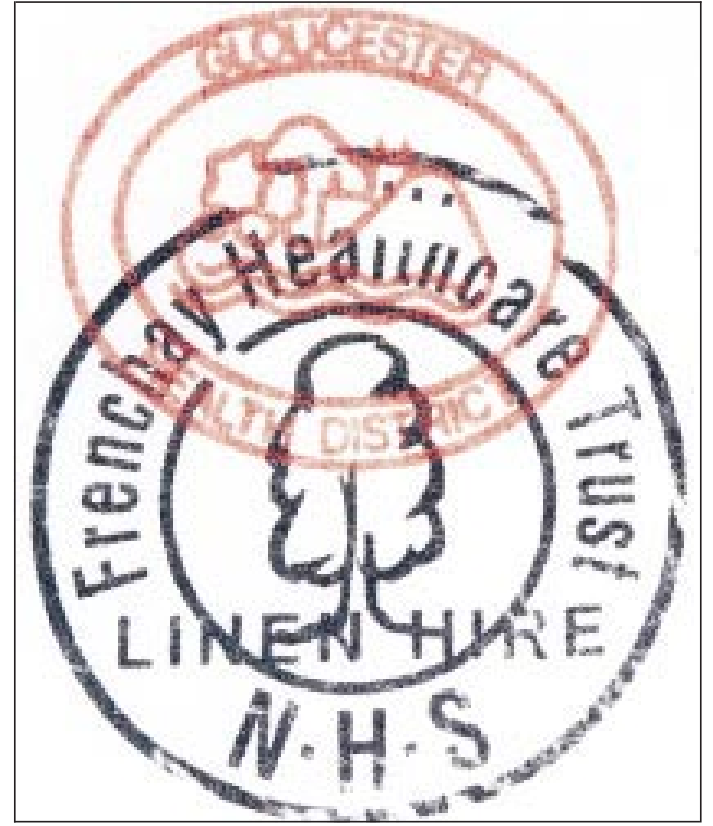

Origin of the linen was attributed to the underlying mark

Two pillowcases each bore two logos, one stamped over the other, and here we attributed the origin to the underlying mark (figure).

\section{Discussion}

There seems to be more to linen loss than theft by staff or patients as lost items clearly remain within the hospital system. The overstamping with a second logo suggests a subsequent claim of ownership, although there is no official trade in secondhand marked laundry.

Some linen observed in Manchester came from north of Birmingham, suggesting a specific northward trend rather than the influence of items from the remote south. Both cities are tertiary centres, drawing referrals from all points of the compass, so it is unlikely that this effect is produced by linen "hitchhiking" with patients. Such a distribution would not be expected by cross contamination within the large laundries that hold contracts with many trusts. The Birmingham based Midland Laundry Group, for example, has contracts with trusts north of the city (P Mellors, personal communication).We believe the universal northward trend of the identifiable alien linen seen in this study deserves further investigation.

Contributors: JR conceived the project, wrote the manuscript, and is the guarantor. PM and SW helped develop the protocol, made the field observations, and helped draw up the manuscript.

Finding: None.

Competing interests: None declared.

1 Holt JL, Hennessey WJ. System for control, monitoring ensures efficient linen use. Hospitals 1978;52(19):183-4.

Rajecki R. Lessening linen loss: Simple steps can stop the "vanishing act." Contemp Longterm Care 1992;15(11):42-4 